Reductionsvermögen eine Substanz auf übermangansaures Kali einwirkt. So zeigt das Chromoxydhydrat ein grölseres Reductionsvermögen als man erwarten sollte; gefälltes, ausgewaschenes und bei gewöhnlicher Temperatur getrocknetes Chromoxyd reducirt schon in der Kälte das übermangansaure Kali unter Bildung von chromsaurem Kali, und bei dem Sieden vollendel sich diese Einwirkung in wenigen Minuten.

\title{
Ueber die Einwirkung von Oxydationsmitteln auf Schwefelcyanverbindungen;
} nach $E$. A. Hadow *).

Uebermangansaures Kali wirkt auf Schwefelcyanmetalle, wenn die Lösung derselben angesäuert ist, in der Art ein, dals nur der Schwefel derselben zu Schwefelsäure oxydirt wird; die wässerige Blausäure wird, wenn eine stärkere Säure zugegen ist, durch übermangansaures Kali nicht verändert, aber in neutraler oder alkalischer Lösung bewirkı sie sogleich Entfärbung desselben. Der Schwefel in Schwefelcyanmetallen wird sehr leicht oxydirt; so selbst in sehr verdünnler Lösung durch Manganhyperoxyd bei Zusatz einer Säure, oder durch Bleihyperoxyd, welches gleichfalls auf eine neutrale Lösung eines Schwefelcyanmetalls nicht einwirkt, aber beiZusalz einer Säure, selbst von Essigsäure, sogleich zu schwefelsaurem Bleioxyd wird. Hadow vermuthet, dafs bei der Einwirkung oxydirender Agentien auf Schwefelcyanmetalle die Bildung einer anderen, weniger Schwefel als das Schwefelcyan ent-

*) Chem. Soc. Qu. J. XI, 174. 
haltenden Cyanverbindung der Bildung von Schwefelsäure vorhergehe, ohne indessen diesen Punkt erledigt zu haben.

Im Beginn der Einwirkung von Salpetersäure auf Schwefelcyanmetalle tritt vorübergehend eine intensive Röthung der Flüssigkeit auf. Reine farblose Salpetersäure zeigt diese Färbung erst bei schwachem Erwärmen, und es bildet sich danı gleichzeitig Schwefelsäure. Rothe salpetrige Dämpfe bringen, in die Lösung eines Schwefelcyanmetalls geleitet, die Röthung sofort hervor, und erst etwas später scheint sich hier Schwefelsäure zu bilden. Reine salpetrige Säure, aus salpetrigsaurem Salz und Essigsäure frei gemacht, röthet die Lösung eines Schwefelcyanmetalls nicht, wohl defshalb, weil die Essigsäure die Schwefelcyanwasserstoffsäure nicht austreibt; eine Lösung von freier Schwefelcyanwasserstoffsäure wird durch die ans salpetrigsanrem Salz und Essigsäure entwickelten Dämpfe geröthet. Dämpfe von Untersalpetersäure bewirken die Röthung, wohl indem $\mathrm{NO}_{4} \mathrm{zu} \mathrm{NO} \mathrm{NO}_{5}$ und $\mathrm{NO}_{3}$ zerfällt, erstere Schwefelcyanwasserstoffsäure frei macht und letztere die rothe Verbindung bildet. Auch bei dem Einleiten der Dämpfe von $\mathrm{NO}_{4}$ in die Lösung eines Schwefelcyanmetalls tritt zuerst rothe Färbung und erst später Bildung von Schwefelsäure ein, wie Hadow durch Versuche mit einer mit einem Barytsalz versetzten Flüssigkeit fand. Die Röthung wird durch Zusatz von Substanzen, die sich mit $\mathrm{NO}_{3}$ verbinden können, von Basen oder selbst von Alkohol, sofort aufgehoben. Hadow glaubt, dals sie auf der Bildung einer nur durch schwache Verwandtschaft veranlalsten Verbindung der salpetrigen Säure beruhe, die der dunkelgefärbten, bei Einwirkung von Stickoxyd auf Eisenoxydulsalze sich bildenden Verbindung vergleichbar sei. 